First Peoples Child \& Family Review

A Journal on Innovation and Best Practices in Aboriginal Child Welfare Administration,

Research, Policy \& Practice

\title{
A Smoking Prevention Program for Aboriginal Youth
}

\section{Daniel McKennitt}

Volume 3, Number 2, 2007

Special Issue: Adolescent development, mental health, and promising research directions for Aboriginal youth

URI: https://id.erudit.org/iderudit/1069463ar

DOI: https://doi.org/10.7202/1069463ar

See table of contents

Publisher(s)

First Nations Child and Family Caring Society of Canada

ISSN

1708-489X (print)

2293-6610 (digital)

Explore this journal

Cite this article

McKennitt, D. (2007). A Smoking Prevention Program for Aboriginal Youth. First Peoples Child \& Family Review, 3(2), 52-55.

https://doi.org/10.7202/1069463ar

\section{Article abstract}

In recent years, policymakers and medical experts have expressed alarm about the growing problem of tobacco related deaths, most specifically from smoking cigarettes. Even more alarming is the rate of tobacco use among Aboriginal people and specifically Aboriginal youth. This paper explores how a holistic approach coupled with Aboriginal healthcare professionals is necessary for an effective smoking prevention program. Moreover, recommendations are provided based on this information to help devise an effective smoking prevention program encompassing all four aspects of health; mental, physical, emotional and spiritual.
This document is protected by copyright law. Use of the services of Érudit (including reproduction) is subject to its terms and conditions, which can be viewed online.

https://apropos.erudit.org/en/users/policy-on-use/ 


\title{
A Smoking Prevention Program for Aboriginal Youth
}

\author{
Daniel McKennitta
}

a Aboriginal Medical Student, Faculty of Medicine and Dentistry, University of Alberta, Edmonton, AB, Canada

\section{Introduction}

Immediately after taking the puff of smoke, our minds would race, and our whole body would be affected by this smoke since tobacco is a very powerful medicine. It has a specific purpose which must not be abused - Elder Danny Musqua (WUNSKA, 1997, p.92)

Smoking is the leading cause of preventable illness and death in Canada and is the known or probable cause of many fatal diseases such as lung cancer, heart disease and stroke. Moreover, smoking is responsible for the death of more than 45,000 Canadians each year. What is even more disturbing is the rate of smoking among Aboriginal people in Canada.

In 2001, more than 1.3 million people identified themselves as Aboriginal, representing approximately $4.4 \%$ of the total population (Statistics Canada, 2003). Tobacco use among Aboriginal persons is at alarmingly high rates as compared with the general population. Recent data has approximately $60 \%$ of First Nations people smoking as compared to $22 \%$ in the general population (National Aboriginal Health Organization - First Nations Centre, 2005). Furthermore, First Nations population-adjusted smoking-attributable mortality rates are almost 1.5 times those of the general population and are responsible for almost one in five adult deaths among First Nations people (Wardman \&

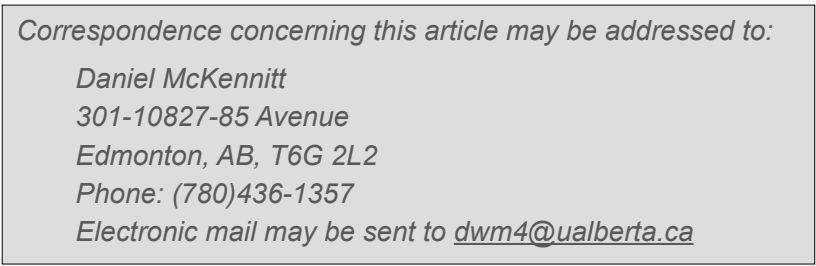

\begin{abstract}
In recent years, policymakers and medical experts have expressed alarm about the growing problem of tobacco related deaths, most specifically from smoking cigarettes. Even more alarming is the rate of tobacco use among Aboriginal people and specifically Aboriginal youth. This paper explores how a holistic approach coupled with Aboriginal healthcare professionals is necessary for an effective smoking prevention program. Moreover, recommendations are provided based on this information to help devise an effective smoking prevention program encompassing all four aspects of health; mental, physical, emotional and spiritual.
\end{abstract}

Khan, 2004). Even more worrisome is the smoking rate among Aboriginal youth, which is 2.0 times higher than in their non-Aboriginal counterparts (Reading \& Allard, 1999). Consequently, there have been smoking interventions and strategies aimed at reversing high smoking rates among Aboriginal youth (Marriott \& Mable, 2002; Ramsden, 2002; Lemchuk-Favel, 2002). These studies unanimously conclude that to maximize effectiveness, Aboriginal youth smoking prevention programs must adopt a holistic approach. Research has also shown that when advised to reduce smoking, adults respond better to healthcare professionals than any other group (Fiore et al., 2000). This paper will discuss relevant areas to consider when developing a smoking prevention program for Aboriginal youth that adopts a holistic approach and centers around healthcare professional utilization.

\section{Holistic Approach}

Aboriginal people tend to take four directions, or four body approaches to health encompassing the physical, mental, emotional and spiritual. Rupert Ross 
(1996) says, “... it is important to approach whatever you encounter in life through all four dimensions" (161). In keeping with the need for a holistic approach, each of the following four areas needs to be addressed to ensure the development and delivery of an effective smoking prevention program for Aboriginal youth.

\section{Culturally Appropriate (Spiritual)}

There are significant challenges when attempting to design and implement a smoking prevention program for Aboriginal youth; one of these being culture, and in particular, the ethic of non-interference. In Aboriginal culture, people are taught to be independent and deal with issues on their own. The cultural practice of non-interference deems asking for help or offering help as culturally inappropriate. This creates serious barriers to the success of existing smoking prevention programs, most of which utilize group presentations to be effective.

Another shortcoming of existing smoking prevention programs is that they tend to isolate smoking from other related substance abuse and addictive behaviour. Smoking is directly related to alcohol dependence and other addictive behaviour including illicit and prescription drug dependence and problem gambling (Emery, Gilpin, Ake, Farkas \& Peirce, 2000; Petry \& Oncken, 2002; Rodda, Brown, \& Phillips, 2004; Shaffer, Vander Bilt \& Hall, 1999; Shiffman \& Balabanis, 1995). This fact is particularly important to consider when developing Aboriginal youth smoking prevention programs. Aboriginal youth they are two to six times more likely to have alcohol-related problems than their non-Aboriginal counterparts (Health Canada, 1999). Further, Aboriginal youth are more likely to experience gambling problems as compared to their non-Aboriginal peers; and teenage Aboriginal problem gamblers are also more likely to be smokers than non problem gamblers of the same age (Hewitt \& Auger, 1995; Peacock, Day \& Peacock, 1999). Thus, Aboriginal youth smoking prevention programs must target these behavioral patterns and taught associations to be effective.

Another major problem with current mainstream smoking cessation programs is the portrayal of tobacco as negative or evil. For Aboriginal people tobacco is a sacred plant used in ceremony and cleansing. Thus, the negative portrayal of tobacco in mainstream smoking cessation programs creates a great deal of tension. When such programs are implemented in
Aboriginal communities, Aboriginal youth have a difficult time accepting the portrayal of a sacred plant as a negative, do not give a full effort, and eventually "tune out" of the program. Aboriginal youth need a smoking prevention program that is both effective and culturally relevant.

\section{Understanding the True Role of Tobacco (Mental)}

To be effective, Aboriginal youth smoking prevention programs must recognize and acknowledge differences between ceremonial tobacco and commercial tobacco use. To illustrate, prior to the arrival of the first Europeans to Canada, Aboriginal people were using tobacco, though not the in way tobacco is used today. Tobacco was a sacred plant and had many uses. For example, tobacco was used for communication with the spirits as a method of seeking the Creator. Tobacco was also used in important ceremonies such as sweat lodges, pipe ceremonies and smudges. In these ceremonies, tobacco was smoked and used as a cleansing ritual. Tobacco was only permitted for ceremonies, as misuse might jeopardize the effectiveness of tobacco in communicating with spirits (Wardman \& Khan, 2005). This understanding is essential in helping Aboriginal youth develop a cultural understanding of tobacco use and the importance of not abusing it.

\section{Targeting Very Young People (Emotional)}

Previous studies suggest that two major risk factors for smoking initiation among children and adolescents include accessibility of tobacco products and perceptions that smoking is a common and normative peer and adult behavior (US Department of Health and Human Services, 1994). In many Aboriginal communities, smoking is perceived to be widespread normal adult behavior. Many youth take up smoking in an attempt to appear "grown up". Aboriginal siblings are usually quite close and very influential in each other's decision-making. Compounding the problem, the trauma of residential schools has left many modern Aboriginal parents with inadequate parenting skills. Targeting youth and their parents will help slow down the snowball effect of smoking uptake and nicotine dependence among youth in Aboriginal communities; a problem that is currently rolling out of control. 


\section{A Smoking Prevention Program for Aboriginal Youth}

\section{Recreation (Physical)}

It is well known that Aboriginal youth desire to participate in culturally relevant recreational and physical activities such as swimming, camping, dancing and exercise. Unfortunately, in many Aboriginal communities funds for recreation and recreation coordinators are either not available or not utilized, and young people find other activities to occupy their time. In one study, it was clearly demonstrated that involvement in sporting activities contributed to lower smoking rates among young Aboriginal athletes (Yakiwchuk et al., 2005). Thus, physical activity is an important part of helping Aboriginal youth to remain smoke free.

\section{Utilizing Healthcare Professionals}

Healthcare professionals play a critical role in reducing tobacco use (US Department of Health and Human Services, 2000). They reach a high percentage of the target population and are in a key position to help smokers change their habits and overcome their difficulties by offering advice and guidance. Additionally, they also have a vital role to play in smoking prevention, especially among youth. The strong, credible voice of health professionals can promote and strengthen the self-confidence and decision-making abilities of youth. Therefore, one strategy to prevent tobacco use is to encourage the involvement of health professionals in tobacco-use prevention programs.

Many Aboriginal healthcare professionals, by the nature of their position, will be required to take leadership positions in Aboriginal health systems, where mainstream approaches will be combined with more traditional health and healing practices (Smylie, 2000). For Aboriginal healthcare professionals, the likelihood of engagement with Aboriginal patients is increased as compared to a non-Aboriginal health care professional (National Aboriginal Health Organization - First Nations Center, 2003). Even more importantly, Aboriginal healthcare professionals are often seen as role models for their communities. As Aboriginal youth commonly lack such role models in their lives, utilizing Aboriginal healthcare professionals as role models within a smoking prevention program is likely to be an effective and even crucial tool in the reduction of Aboriginal youth smoking rates.

Finally, the development and implementation of effective Aboriginal youth smoking prevention pro- grams must involve consultation with Aboriginal youth themselves. Aboriginal youth must be given the opportunity to be the leaders as well as the participants of such initiatives in order for these programs to be effective. Allowing youth a place in the creative process creates a feeling of ownership that reduces drop out rates and increases the overall success of the program. Moreover, the development of a holistic smoking prevention program that utilizes Aboriginal healthcare professionals and includes Aboriginal youth in the creative process is a unique approach that holds promise but has yet to be developed and targeted at Aboriginal youth in Canada.

\section{Bio}

Daniel McKennitt comes from the Sandy Bay Ojibway First Nation, just outside of Winnipeg, Manitoba. Daniel recently finished his first of year of medical school at the University of Alberta. Before this, Daniel completed his Bachelor of Science degree at the University of Alberta with a double major in Mathematics and Physical Sciences. Inspired by his mother, a residential school survivor and breast cancer survivor, Daniel became interested in improving the health and success of Aboriginal youth in all aspects of life. Previously working with institutions such as the University of Alberta, Alberta Advanced Education, and Canadian Heritage; Daniel brings a wealth of knowledge in regards to working with Aboriginal youth to achieve their goals. Lastly, Daniel was just named one of twelve National Aboriginal Health Organizations youth role models for the 2006-2007.

\section{References}

Emery, S., Gilpin, E., Ake, C., Farkas, A., \& Peirce, J. (2000). Characteristics and identifying 'HardCore' smokers: Implications for further reducing smoking prevalence. American Journal of Public Health, 90, 387-394.

Fiore, M., Bailey, W., Cohen, S., Dorfman, S., Gritz, E., Heyman, R., Holbrook, J., Jaen, C., Kottke, T., Lando, H., Mecklenbur, R., Mullen, P., Nett, L., Robinson, L., Stitzer, M., Tommasello, A., Villejo, L., \& Wewers, M. (2000). Treating tobacco use and dependence. Clinical practice guideline. Rockville, MD: U.S. Department of Health and Human Services. Public Health Service.

Health Canada. (1999). First Nations Inuit Health Branch. A Second Diagnostic on the Health of 
First Nations and Inuit People in Canada. Ottawa, ON: Minister of Health.

Hewitt, D., \& Auger, D. (1995). Firewatch on Aboriginal adolescent gambling. Edmonton, AB: Nechi Training, Research and Health Promotion Institute.

Lemchuk-Favel, L. (2002) Peers and Fears: Aboriginal Youth and Tobacco Reduction Strategies: Implications for Social Marketing (Unpublished).

Marriott, J., \& Mable, A. (2002) Aboriginal Tobacco Control Promising Strategies and Potential for Best Practices. Ottawa, ON: First Nations and Inuit Tobacco Control Strategy (FNITCS), Health Canada - First Nations and Inuit Health Branch \& National Aboriginal Health Association, (Unpublished, Draft).

National Aboriginal Health Organization - First Nations Center. (2003). Public Opinion Poll First Nations Views on Their Health and Health Care, (Preliminary results). Ottawa, ON: Author.

National Aboriginal Health Organization- First Nations Centre. (2005). First Nations regional longitudinal health survey (2002/03). Ottawa, ON: Author.

Peacock, R., Day, P., \& Peacock, T. (1999). Adolescent gambling on a great lakes Indian reservation. Journal of Human Behavior in the Social Environment, 2(1/2), 5-17.

Petry, N., \& Oncken, C. (2002). Cigarette smoking is associated with increased severity of gambling problems in treatment-seeking gamblers. Addiction, 97, 745-753.

Ramsden, V. (2002). Building Best Practices with Community. First Nations and Inuit Tobacco Control Strategy (FNITCS). Ottawa, ON: Health Canada - First Nations and Inuit Health Branch (Unpublished, Draft).

Reading, J., \& Allard, Y. (1999). The Tobacco Report: Report of the FNIRHS. Ottawa, ON: First Nations and Inuit Health Survey National Steering Committee.

Rodda, S., Brown, S., \& Phillips, J. (2004). The relationship between anxiety, smoking, and gambling in electronic gaming machine players. Journal of Gambling Studies, 20(1), 71-81.

Ross, R. (1996). Return to the teachings: Exploring Aboriginal justice. Toronto, ON: Penguin Books.

Shaffer, H., Vander Bilt, J., \& Hall, D. (1999). Gambling, drinking, smoking and other health risk activities among casino employees. American Journal of Industrial Medicine, 36, 365-378.

Shiffman, S. \& Balabanis, M. (1995). Associations be- tween alcohol and tobacco. Chapter 2 in Fertig, J.B., Allen, J.P. (Eds.), Alcohol and Tobacco: From Basic Science to Clinical Practice (Research Monograph \#30). Bethesda, Maryland: NIAAA

Smylie, J. (2000). A guide for health professionals working with Aboriginal peoples. Society of Obstetricians and Gynecologists of Canada. No. 100.

Statistics Canada. (2003). 2001 Census: Analysis Series. Aboriginal Peoples of Canada: A Demographic Profile. Ottawa, ON. Accessed May 4, 2007. http://www. statcan.ca/english/IPS/Data/96F0030XIE2001007. $\underline{\mathrm{htm}}$

U.S. Department of Health and Human Services. (1994). Preventing tobacco use among young people: A report of the Surgeon General. Atlanta, Georgia: U.S. Department of Health and Human Services, Public Health Service, Centers for Disease Control and Prevention, National Center for Chronic Disease Prevention and Health Promotion, Office on Smoking and Health.

US Department of Health and Human Services. (2000). Reducing tobacco use: a report of the Surgeon General. Atlanta, Georgia: U.S. Department of Health and Human Services, Public Health Service, Centers for Disease Control and Prevention, National Center for Chronic Disease Prevention and Health Promotion, Office on Smoking and Health.

WUNSKA. (1997). First Nations Youth Inquiry into Tobacco Use: Final Comprehensive Report to Health Canada. Saskatchewan: Saskatchewan Indian Federated College.

Wardman, D., \& Khan, N. (2004). Smoking-attributable mortality among British Columbia's First Nations populations. International Journal on Circumpolar Health, 63, 81-92.

Wardman, D., \& Khan N. (2005). Registered Indians and tobacco taxation: A culturally appropriate strategy? (Commentary). Canadian Journal of Public Health, 96, 451-453.

Yakiwchuk, C., Stasiuk, H., Wiltshire, W., \& Brothwell. D. (2005). Tobacco Use among young North American Aboriginal athletes. Journal Canadian Dental Association, 71, $403 \mathrm{a}-403 \mathrm{~d}$. 